\title{
Trajetória Dependente e Subordinada: Elementos da Singularidade do Atraso Inovativo Brasileiro
}

\section{Dependent and Subordinate Trajectory: Elements of the Singularity of Brazilian Innovative Delay}

\author{
Adriano Pereira* \\ Herton Castiglioni Lopes**
}

\begin{abstract}
Resumo: Na perspectiva institucionalista evolucionária, a dinâmica inovativa constitui o epicentro da transformação nas economias capitalistas. Entende-se que essa perspectiva teórica possibilita uma abordagem das trajetórias econômicas nacionais a partir das suas singularidades, contribuindo para a análise do atraso relativo de economias como a brasileira ao demonstrar que esta tem se caracterizado por uma posição dependente e ao mesmo tempo subordinada no que se refere aos processos inovativos permanentemente em curso na economia internacional. Considera-se que, apesar de contribuir para as inovações do ponto de vista sistêmico, pelo menos desde a década de 1950 o Brasil apresenta dificuldades de desenvolver processos inovativos endogenamente, sobretudo em função da forma como as empresas estrangeiras se inseriram na indústria nacional desde o início da segunda metade do século XX.
\end{abstract}

Palavras-chave: Inovação. Dependência. Subordinação. Economia brasileira.

\begin{abstract}
In the institutionalist evolutionary perspective the innovative dynamics constitutes the epicenter of the transformation in the capitalist economies. It is understood that this theoretical perspective makes it possible to approach the national economic trajectories from their singularities, contributing to the analysis of the relative backwardness of economies such as the Brazilian one demonstrating that it has been characterized by a dependent and at the same time subordinate position, with regard to the innovative processes constantly under way in the international economy. It is considered that, despite contributing to systemic innovations, at least since the 1950s, Brazil has had difficulties in developing endogenous innovative processes, mainly due to the way in which foreign companies have been involved in the domestic industry since the beginning of the second half of the twentieth century.
\end{abstract}

Keywords: Innovation. Dependency. Subordination. Brazilian economy.

JEL Classification: O14; O33; P1.

\footnotetext{
* $\quad$ Doutor em Desenvolvimento Econômico pela Universidade Federal do Rio Grande do Sul (UFRGS). Professor associado do Departmaneto de Economia e Relações Internacionais da Universidade Federal de Santa Maria (UFSM). E-mail: adrianoeconomia@ufsm.br

** Doutor em Desenvolvimento Econômico pela UFRGS. Professor adjunto da Universidade Federal da Fronteira Sul (UFFS). E-mail: herton.lopes@uffs.edu.br
} 


\section{1 lntrodução}

A forma como o Brasil acelerou o seu processo de industrialização, a partir da década de 1950, com base na atração de capital estrangeiro, via investimento externo direto (IED), se tornaria um condicionante do seu desenvolvimento econômico no longo prazo. Nesse sentido, é importante compreender por quais motivos a industrialização nacional, com significativa participação das empresas transnacionais (ETNs), oriundas de economias avançadas, não criaria uma profusão de processos inovativos dentro das fronteiras nacionais, no longo prazo, dado o potencial tecnológico dessas empresas.

Estudos recentes, como os de Arend e Fonseca (2012), Arend (2014), Cassiolato et al., (2014), Pereira e Dathein (2015), Chiarini (2016), Strachman, (2016), entre outros, têm corroborado, em essência, algumas análises mais antigas, como as de Furtado (1950, 1980, 2002), Evans (1980), Dahlman (1984), Tavares, (1998), entre outros, sobre a dependência estrutural da indústria brasileira em relação ao capital produtivo estrangeiro e seus efeitos negativos no longo prazo, sobretudo no que se refere à inovação tecnológica.

O objetivo principal deste artigo é analisar esse processo de forma retrospectiva, e em perspectiva histórica, para uma compreensão mais adequada de fenômenos contemporâneos, como a inserção do Brasil nas cadeias globais de valor (CGVs) (STURGEON et al., 2013; ARAÚJO JÚNIOR, 2013; FERRAZ et al., 2015), bem como o processo de desindustrialização porque vem passando a economia brasileira desde a década de 1980 (NASSIF, 2008; OREIRO; FEIJÓ, 2010; CANO, 2012), como eventos sistêmicos, que se dão ao mesmo tempo que as economias nacionais apresentam singularidades em suas trajetórias. Em termos específicos, como contribuição deste artigo, pretende-se analisar como as ETNs têm afetado as mudanças estruturais na economia brasileira de forma a contribuir para as inovações. Em outras palavras, como os processos inovativos no Brasil estariam condicionados aos eventos sistêmicos capitaneados pelas ETNs, dado que essas empresas foram agentes centrais da mudança estrutural na economia nacional nas duas tentativas de catching up nos anos 1950 e 1990 (CASTRO, 2003). Nesse sentido, a análise em perspectiva histórica propõe-se a contribuir para uma avaliação da situação da economia brasileira, no início do século XXI, considerando-se as duas opções de desenvolvimento adotadas na segunda metade do século XX, em que houve destaque para o capital estrangeiro.

Entende-se que, como epicentro da transformação econômica, as inovações afetam todas as economias capitalistas, de formas e intensidades diferenciadas. Trata-se de um processo sistêmico, ainda que a origem dos principais processos inovativos continue concentrada em economias desenvolvidas (em virtude dos sistemas nacionais de inovação, conhecimento tácito etc.), a exemplo do que 
ocorre com a renda e a riqueza. Nesse sentido, economias retardatárias, como a brasileira, têm se caracterizado, historicamente, como importantes absorvedoras de inovações geradas exogenamente (no exterior), como se o acesso à tecnologia física fosse condição suficiente para a geração de inovações endogenamente (dentro das fronteiras nacionais). Reunir subsídios para a compreensão da complexidade desse processo, fora da mainstream economics (corrente dominante) - que entende que as economias tenderiam a um processo de convergência ao industrializarem-se, inclusive com atração de capital estrangeiro -, tem sido uma contribuição fundamental do institucionalismo evolucionário. Por esse motivo, trata-se de um importante referencial teórico, alternativo, para o estudo do atraso relativo de economias como a brasileira, que, a despeito de terem acesso às tecnologias geradas exogenamente, sobretudo via ETNs, têm apresentado limitações no desenvolvimento de processos inovativos endogenamente, ainda que continuem importantes para o capitalismo enquanto sistema.

Ao retomar parcialmente os argumentos de Joseph Schumpeter, sob a influência de Karl Marx, a abordagem institucionalista evolucionária - que engloba neoinstitucionalistas (herdeiros do velho institucionalismo) ${ }^{1}$ e neoschumpeterianos (evolucionários) - viria a reforçar a importância da interação entre os diferentes tipos de inovação (materiais e imateriais) para a mudança econômica. Este artigo tem como ponto de partida esse legado, que tem sua origem em Marx, cuja influência perpassa a obra de Schumpeter, sobretudo no que se refere à concepção de evolução capitalista e seu epicentro: a inovação tecnológica. ${ }^{2}$

Tomando-se como base a perspectiva institucionalista evolucionária, considera-se o papel das instituições na transformação econômica, com destaque para a empresa (instituição que "materializa a ordem capitalista") ${ }^{3}$ e seu contexto de interação. Trata-se, portanto, da compreensão de que o avanço tecnológico tem estado condicionado pelos diferentes arranjos institucionais vigentes que, ainda que não sejam os mesmos dos tempos de Marx ou de Schumpeter, continuam contribuindo para preservar condições básicas para o permanente processo de transformação: a "destruição criativa" segue em curso, ainda que com caráter mais conservador (em sentido oposto a revolucionário), se comparado ao período em que Schumpeter (1997b) enfatizava a importância central do empresário inovador na dinâmica concorrencial.

1 Ver Hodgson (1993).

2 Sabe-se que há uma estreita relação entre dinâmica inovativa e capital financeiro, tanto no que se refere à geração quanto à difusão de inovações, como um processo característico das "ondas longas" do capitalismo. Este artigo não aborda essa questão diretamente, limitando-se a uma discussão sobre o processo inovativo e seus reflexos no desempenho da dinâmica produtiva capitalista, com ênfase no setor industrial. Para uma abordagem evolucionária da relação entre inovação e capital financeiro, ver Perez (2004); para uma síntese sobre o significado dos ciclos e "ondas", ver Freeman (1984).

3 Ver Schumpeter (1961). 
Entende-se que a destruição criativa consolidou-se como uma mudança estrutural dependente dos arranjos institucionais vigentes, confirmando a multidimensionalidade (CASSIOLATO; LASTRES, 2005) das diferentes formas de inovação (tecnológicas, organizacionais e institucionais), ainda que as tecnologias físicas continuem exercendo uma primazia relativa no processo de mudança, pelo menos de forma aparente. Dessa forma, conceber as tecnologias como físicas e sociais (NELSON, 2002) tem contribuído para uma compreensão mais adequada do processo evolutivo do capitalismo contemporâneo, que tem sobrevivido às crises e à concentração de capital. Por sua vez, torna-se fundamental analisar o modo como as diferentes economias nacionais têm aderido a esse processo de mudança estrutural, baseado na articulação existente entre as diferentes formas de inovação.

Este artigo está dividido em mais três seções, além desta introdução: a segunda apresenta uma breve síntese do pensamento de Schumpeter, influenciado por Marx, destacando o que se considera um dos aspectos mais relevantes na herança marxista-schumpeteriana do institucionalismo evolucionário: as inovações tecnológicas como epicentro do processo evolutivo e sua relação com outras formas de inovação, compatíveis com a necessidade de transformação permanente, ainda que conservadora, do capitalismo; a terceira seção é dedicada ao resgate de alguns elementos que caracterizam o atraso inovativo do Brasil, em função da opção deliberada pela industrialização baseada em grandes estruturas produtivas empresariais, em que acabariam se destacando as empresas de capital estrangeiro como principal alternativa de desenvolvimento econômico; e, para finalizar, a última seção apresenta algumas considerações finais.

\section{Institucionalismo Evolucionário em Economia: uma Síntese}

Há evidências explícitas e implícitas da influência da obra de Karl Marx sobre Joseph Schumpeter, ainda que este tenha se caracterizado pela singularidade do que se tornaria o pensamento schumpeteriano, sobretudo no que se refere a sua influência sobre a formação e consolidação da corrente de pensamento evolucionária em Economia.

Ressalta-se que, enquanto Marx se notabilizou como um crítico do capitalismo em toda a sua obra, Schumpeter ressaltou a importância do sistema (em termos de inovações e seus efeitos positivos) em grande parte dos seus trabalhos (pelo menos até a publicação da primeira edição de Capitalismo, socialismo e democracia, em 1942). Ainda assim, Schumpeter (1961) reconhece em Marx um importante analista do funcionamento da economia capitalista como um processo evolutivo, em permanente transformação, uma das ideias centrais que permeia a 
obra dos dois autores e que acabaria servindo de base para a abordagem teórica institucionalista evolucionária. ${ }^{4}$

A exemplo de Marx (1983), para Schumpeter (1961, 1997a, 1997b), a inovação compreende aspectos estruturais (tecnológicos e organizacionais) e institucionais, que tomaram uma dimensão ascendente a partir da industrialização das economias, como algo inerente à evolução capitalista. A busca de uma maior compreensão da relação entre esses aspectos, no que se refere às questões essencialmente econômicas, tem suscitado algumas análises da influência da obra de Marx sobre o pensamento de Schumpeter.

Como tem sido ressaltado em tempos mais recentes (ELLIOT, 1980; FOSTER, 1984; SALOMON, 1991; ROSENBERG, 2006; AYDIN; TAKAY; OZIL, 2010), tornou-se ainda mais relevante o reconhecimento da importância de Marx por parte de Schumpeter, na medida em que as comparações entre esses autores transcendem a esfera econômica das suas análises sobre o capitalismo. Trata-se de dois autores que se dedicaram ao tratamento da Ciência Econômica de forma articulada e integrada a outros campos do conhecimento (história, política, sociologia, filosofia, etc.) que também buscam a análise do funcionamento do sistema capitalista, ainda que dediquem parte fundamental de suas obras à compreensão da dinâmica produtiva centrada no desejo/necessidade do avanço tecnológico como mecanismo de obtenção de lucro e de acumulação de capital.

Tratando-se especificamente da inovação tecnológica, um destaque da obra de Marx (1983) consiste no tratamento dos aspectos econômicos relacionados à busca da acumulação, o que acabou influenciando a visão schumpeteriana de progresso técnico movido pelo desejo do lucro. A inovação representa uma redução do custo produtivo (poupança de trabalho em Marx) fundamental para a obtenção de lucro em um cenário concorrencial. Entretanto, tanto para Marx, quanto para Schumpeter, a inovação é fruto de um processo social: ${ }^{5}$ não possui caráter neutro ou, mesmo, natural, pois é resultante de um processo intencional, movido por objetivos concretos. Por sua vez, a necessidade de criação e aperfeiçoamento de mecanismos de difusão tecnológica não implica, necessariamente, a difusão dos processos inovativos. Nesse sentido, Marx e Schumpeter veem na concentração de capital tanto um objetivo quanto um resultado da dinâmica inovativa. Observa-se que, ao analisarem a dinâmica evolutiva do capitalismo, nenhum dos dois autores trata o avanço tecnológico como determinante da mudança econômica, mas como aspecto central das transformações materiais que

4 Para um resgate histórico do evolucionismo em Economia, faz-se necessário considerar a influência da obra de Charles Darwin sobre autores como K. Marx, T. Veblen e J. Schumpeter, entre outros, o que foge ao escopo deste artigo.

5 A inovação é considerada um processo social, ainda que se trate, originalmente, de uma realização individual, como ressaltado por Schumpeter (1961), a partir de seu destaque para a função do empresário inovador que, inevitavelmente, está inserido em um determinado contexto. 
afetam ao mesmo tempo que são afetadas pelos aspectos institucionais (inclusive os de natureza organizacional). Portanto, não há um determinismo tecnológico na evolução capitalista. Para ambos, a inovação é um mecanismo que tem no lucro o seu objetivo principal, daí resultando, entre outros fatores, a acumulação e a concentração do capital, o que levaria à busca por mais inovação. Como destaca Schumpeter (1961, p. 56), Marx "Uniu habilmente a concentração ao processo de acumulação, ou antes, considerou a primeira como parte da última e não somente como parte de sua estrutura, mas também de sua lógica.".

A contribuição desses dois autores foi fundamental para a análise do capitalismo a partir de uma abordagem centrada na sua dinâmica evolutiva, em oposição declarada ao mainstream economics e sua abordagem estática do avanço produtivo e tecnológico e, por conseguinte, do desenvolvimento econômico considerado como um simples acúmulo de riquezas. ${ }^{6}$

A tecnologia é concebida, tanto por Marx, quanto por Schumpeter, ${ }^{7}$ como um mecanismo de acumulação de riqueza, porém gestado endogenamente ao sistema econômico: as tecnologias são físicas e também sociais, portanto não se limitam a uma questão de engenharia produtiva e reprodução de estruturas materiais. As causas da mudança capitalista são de natureza endógena: são econômicas, sociais, políticas, históricas e, portanto, institucionais. O ambiente a partir do qual as inovações tecnológicas são geradas e direcionadas é fundamental para a dinâmica evolutiva da economia capitalista, ou seja, a destruição criativa tem caráter institucional (SCHUMPETER, 1947, 1961).

Schumpeter (1961, p. 109) ressalta que o capitalismo é um processo evolutivo, “[...] conforme enfatizado há tanto tempo por Karl Marx [...]”, em que as inovações constituem-se no fator central da evolução, tendo nas empresas (oligopólios, predominantemente) os agentes principais dessas transformações, que têm estado condicionadas ao ambiente macroinstitucional. Nessa visão, inserem-se vários fatores, que reforçam o caráter sistêmico dos processos inovativos. Como ilustra Schumpeter (1961, p. 111) em uma passagem emblemática de sua obra: "[...] normalmente se vê o problema de como o capitalismo administra as estruturas existentes, enquanto o relevante é saber como ele as cria e destrói.".

Especificamente no caso de Schumpeter (1947, 1961, 1997a), entende-se que, apesar da ênfase dedicada às questões tecnológicas físicas, o autor, a partir da influência de Marx, caracteriza-se também pelo entendimento de que o contexto social afeta e é afetado pelas inovações tecnológicas em seu conjunto. Portanto,

6 Retratado, em certa medida, na reprodução simples (MARX, 1983) e no fluxo circular (SCHUMPETER, 1997b).

7 De fator exógeno, relacionado ao empresário inovador, a inovação passaria a ser tratada por Schumpeter (1961) como fator endógeno, gestado internamente, sobretudo na grande empresa oligopolista a qual, por sua vez, constitui-se em um dos resultados da concentração de capital como processo histórico, em curso permanente. 
as instituições importam para Schumpeter, assim como importaram para Marx, ainda que ambos não tenham se dedicado, diretamente, à sua análise quando do tratamento dos aspectos tecnológicos da mudança econômica. Nesse sentido, identifica-se em Schumpeter, a partir de Marx, a essência da relação entre inovação tecnológica e evolução capitalista como dois aspectos centrais da dinâmica sistêmica ao longo da História, que persistem a despeito da incessante concentração de capital e das sucessivas crises econômicas.

Em síntese, tanto Marx quanto Schumpeter contribuíram para a compreensão do modo de produção (essencialmente no que se refere aos aspectos materiais, em termos mais específicos, à estrutura produtiva/forças produtivas) e do sistema capitalista contemporâneo a partir de uma visão multidimensional (considerando as relações entre as diferentes formas de inovação e sua interdisciplinaridade) acerca da sua dinâmica evolutiva. Esse caráter analítico tem sido adotado pelo institucionalismo evolucionário como uma herança teórico-conceitual que vem de Schumpeter, sob influência de Marx.

Para Nelson (2002), além de Schumpeter, economistas como Adam Smith, Karl Marx e Alfred Marshall caracterizaram-se por abordagens tanto institucionalistas quanto evolucionárias. No entanto, o predomínio da teoria econômica neoclássica ao longo da maior parte do século XX teria contribuído para que houvesse uma separação, fora do mainstream, entre aqueles que, como Commons (1931) e Coase (1937), optaram por uma abordagem institucional da mudança econômica, ao passo que autores como Schumpeter (1997b) teriam optado por um enfoque centrado nos aspectos tecnológicos. Essa separação passaria a ser desfeita, conforme Nelson (2002), somente no final do século XX, quando da necessidade de juntar as perspectivas institucionalista e evolucionária para um tratamento analítico mais adequado da dinâmica do crescimento econômico capitalista.

$\mathrm{Na}$ perspectiva institucionalista evolucionária, considera-se como instituições, em um sentido mais abrangente, o conjunto de hábitos, costumes, rotinas, etc. adotados em um determinado contexto, que exerce efeitos sobre o comportamento dos indivíduos, os quais, ao interagirem com as instituições, acabam produzindo uma trajetória de transformação permanente. Como ressaltado por Commons (1931), uma instituição é uma ação coletiva que controla, libera ou amplia a ação individual. Portanto, ocorre interação entre instituições e indivíduos, bem como entre os indivíduos através das instituições e destas entre si. Não há determinismo, mas condicionalidade, ou seja, as trajetórias são dependentes (path dependent).

Assim como ocorre com os indivíduos, as instituições mudam e se desenvolvem em função dos estímulos derivados das circunstâncias em que se encontram. De acordo com Veblen (1965), são hábitos mentais que orientam a forma de ação dos indivíduos, que, por sua vez, contribuem ativamente para o desenvolvimento 
institucional à medida que afetam, a partir de seus hábitos, o contexto em que se inserem. Portanto, os hábitos de pensamento são fundamentais para se compreender a atitude dos indivíduos bem como a mudança institucional.

Como ressaltado por Veblen (1965), as instituições do presente são moldadas conforme a influência exercida sobre os indivíduos, que, por sua vez, fazem escolhas acerca das instituições que serão adotadas, reformuladas ou abandonadas. Portanto, as escolhas são condicionadas pelo ambiente de interação, em que as instituições são, ao mesmo tempo, condicionantes e resultantes do processo seletivo. Mais especificamente, as instituições econômicas "[...] são métodos habituais de dar continuação ao modo de vida da comunidade em contato com o ambiente material no qual ela vive" (VEBLEN, 1965, p. 182). Nesse sentido (influenciado por Karl Marx), Veblen (1965) considera que a forma como a sociedade se organiza para produzir suas condições materiais de existência tem forte influência sobre a maneira como suas instituições sociais e econômicas evoluem: as "forças de reajustamento" das instituições na comunidade industrial são principalmente forças econômicas. ${ }^{8}$ A mudança institucional estaria relacionada à ação humana, que, por sua vez, é influenciada pelas condições materiais de vida. Desse modo, os aspectos econômicos afetam e são afetados pelos não econômicos, ainda que não no mesmo sentido e intensidade, além de a relação de causalidade não ser linear nem predeterminada. Não há determinismo econômico a exemplo do que se identifica em Marx e em Schumpeter. O processo de mudança é dinâmico e multidirecional, ainda que as instituições econômicas tenham um papel fundamental, inclusive no que se refere à manutenção (inércia) das regras (formais e informais) vigentes.

Assim como as mudanças estruturais, identificadas na concepção de desenvolvimento econômico de Schumpeter (1997b), as mudanças institucionais afetam o desempenho das economias, influenciando os ritmos e os rumos de tais transformações, ou seja, a forma como o crescimento econômico é permeado por outras mudanças, que, em conjunto, permitem a ocorrência do desenvolvimento no longo prazo, ou entravam esse processo.

As instituições estão sempre em evolução, sendo os agentes econômicos condicionados pela sua própria trajetória, ao mesmo tempo que desenvolvem a capacidade de promover transformações. Essas transformações, ou a mudança, não são necessariamente para melhor: pelo contrário, as "instituições imbecis" (VEBLEN, 1965) podem ser tão importantes e duradouras (inércia) ${ }^{9}$ quanto as demais.

$8 \quad$ Nas palavras de Schumpeter (1961, p. 32, grifo nosso): “[...] os homens escolhem sua maneira de agir, que não é diretamente imposta pelos dados objetivos do ambiente. Mas a escolha é feita com base em princípios, opiniões e propensões que não formam um conjunto de dados independentes, mas são, eles próprios, moldados pelo conjunto objetivo."

9 Segundo Veblen (1965, p. 180), “[...] os hábitos mentais dos homens hodiernos tendem a persistir 
Portanto, os fatores institucionais, ao afetarem e serem afetados pelos fatores estruturais (inovações tecnológicas e organizacionais), promovem a mudança econômica em uma perspectiva institucionalista evolucionária. Nessa abordagem, de forma distinta da proposta originalmente por North (1993), ${ }^{10}$ entende-se que as instituições devem ser consideradas sob a forma de regras do jogo, mas também sob a forma de organizações, tais como as empresas capitalistas e sua incessante busca pela inovação, que têm se caracterizado como meio e fim da evolução capitalista, em uma espécie de "gnosticismo tecnológico" (MARTINS, $2011^{11}$ apud CAMPOLINA; DINIZ, 2014). Hodgson (2006) argumenta que as organizações (firmas) também devem ser tratadas como instituições, mas com características que as distinguem das demais. ${ }^{12}$

Para Schumpeter (1961) e Penrose (2006), assumir a diversidade de tipos e de comportamentos das empresas como regra transformou-se em um ponto de partida fundamental para a argumentação evolucionária (neoschumpeteriana) sobre a dinâmica econômica agregada. Considerar as diferentes facetas da empresa, como instituição, tem se constituído no núcleo da análise em relação aos efeitos do seu comportamento sobre o desempenho das diferentes economias. ${ }^{13}$

Por mais que uma empresa empregue estratégias conscientes para guiar suas ações, sempre haverá algum grau de subjetividade no tratamento da realidade, em

indefinidamente, exceto quando as circunstâncias obrigam a uma mudança. Essas instituições assim herdadas, esses hábitos mentais, pontos de vista, atitudes e aptidões mentais, ou seja lá o que for, são, portanto, um elemento conservador; e este é um fator de inércia social, de inércia psicológica, de conservantismo.".

10 North (1993), um dos principais expoentes da Nova Economia Institucional (NEI), entende que as instituições são as "regras do jogo", ao passo que os indivíduos e as organizações são os "jogadores". A NEI, representante institucionalista do mainstream economics, aborda as instituições a partir de seu caráter contratual (formal e informal), por isso se dá a divisão de funções entre as regras e aqueles que deveriam seguí-las, em função de uma maior eficiência nas relações econômicas. Para um contraste entre as principais diferenças da abordagem da NEI em relação ao institucionalismo evolucionário, ver Pereira, Dathein e Conceição (2014).

11 MARTINS, H. Experimentum humanum: civilizaçãotecnológica e condição humana. Lisboa: Relógio D'Água Editores, 2011.

12 Segundo Hodgson (2006), as organizações são instituições especiais que envolvem: a) o critério para estabelecer suas fronteiras e distinguir os seus membros dos não membros; b) princípios de poder em relação a quem está no comando; e c) cadeias de comando, delineando responsabilidades para dentro da organização.

13 Uma contribuição fundamental de Penrose (2006), importante referência evolucionária, está justamente na ênfase que a autora dedica aos aspectos relativos ao funcionamento interno da empresa (em um contexto em que a empresa era concebida na esfera econômica, predominantemente, como uma "caixa preta"), a partir de uma abordagem econômica dos fatores que determinam o seu comportamento e a sua expansão, em função do uso de recursos materiais e humanos e da importância do conhecimento relacionado às atividades produtiva, administrativa e empreendedora. Conforme Penrose (2006, p. 230): “[...] a firma constitui essencialmente um reservatório de recursos cuja utilização é realizada por meio de um arcabouço administrativo.". Nesse sentido, a autora destaca a necessidade da análise da empresa tanto a partir de seu interior, quanto da forma como essa utiliza os seus "recursos disponíveis" para atuar frente à concorrência no mercado, ambos considerados "instituições" em transformação permanente e interligada. 
função da incerteza e da racionalidade limitada dos agentes, além dos imprevistos associados ao ambiente. Como observam Nelson e Winter (2005, p. 64), "[...] o mundo econômico é por demais complicado para que a firma o compreenda perfeitamente [...]." Com base nisso, o resultado do processo de busca e seleção é que dirá em que medida a empresa adotou uma estratégia compatível com a realidade observada, a partir das suas próprias condições produtivas, organizacionais e institucionais, ou seja, a partir das suas condições internas e da sua interatividade.

À medida que optam por uma determinada estratégia tecnológica, as empresas precisam criar condições organizacionais compatíveis para tornarem-se viáveis. Nesse sentido, a inovação tecnológica está diretamente associada às inovações organizacionais e institucionais ao criar novas formas de interação da empresa com o ambiente em que se insere e dos indivíduos com seu interior. Coriat e Dosi (2007), por exemplo, afirmam que a história evolucionária acontece em complementaridade com aspectos institucionais. Em outras palavras, inovações precisam de um ambiente institucional adequado para sua propagação (tecnologias sociais e sistema nacional de inovações), assim como de estruturas institucionais e de regulação que garantam demanda para as inovações em desenvolvimento.

Nesse sentido, organizações (como as empresas) possuem um conjunto de mecanismos que possibilitam a reprodução de hábitos e rotinas, exercendo um importante papel sobre o comportamento dos indivíduos em seu interior, mas também fora dele (HODGSON, 2006). Enquanto as rotinas são, no ambiente interno das firmas, o conjunto de hábitos que garante a operacionalização, o avanço das tecnologias e os estímulos para inovação, no ambiente externo são os mecanismos que mantêm a estrutura institucional da sociedade. Não por acaso, Hodgson (2006) define instituições como um sistema de regras que estruturam as relações sociais, sendo o hábito o elemento-chave no entendimento de como as regras são enraizadas na sociedade, mantendo sua estrutura de funcionamento. A dinâmica capitalista, portanto, transcende a esfera produtiva e de realização da produção, como já havia sido enfatizado por Marx e Schumpeter.

Seja através de regras formais ou informais, as organizações criam uma estrutura social e um ambiente físico no qual os indivíduos estão inseridos e a partir do qual estes moldam seus hábitos de pensamento e ação, transformando-os em rotinas. ${ }^{14}$ As rotinas caracterizam a situação em que os hábitos se transformam em regras (formais e informais), organizadas e seguidas institucionalmente, sendo, por isso, fundamentais para o desenvolvimento do processo de aprendizado.

Por sua vez, as capacitações e competências organizacionais da firma são fundamentais para determinar os seus resultados, tanto no que se refere a sua

14 Como observa Hodgson (2007, p. 111): "Individuals have habits; groups have routines. [...] Routines are irreducible to habits alone: they are organizational meta-habits, existing on a substrate of habituated individuals in a social structure." 
lucratividade e crescimento, quanto a sua probabilidade de sobrevivência (CORRIAT; DOSI, 2002). De acordo com Coriat e Dosi (2002), duas questões fundamentais devem ser levadas em consideração para a compreensão da natureza das competências e capacitações organizacionais: o contexto em que as organizações estão inseridas e a forma como afetam as habilidades e o conhecimento de seus membros.

Em síntese, a empresa é a unidade central de análise para a abordagem institucionalista evolucionária em virtude de se constituir no locus principal da geração (em um processo de destruição criativa, via acumulação de conhecimentos), adaptação e uso das inovações e do processo de aprendizado, como eventos coletivos (organizacionais). ${ }^{15}$ É nesse sentido que "materializa a ordem capitalista" (SCHUMPETER, 1961). Disso resultam duas conclusões evolucionárias fundamentais: a inovação tecnológica é fator fundamental para a mudança econômica e o ambiente com o qual a empresa interage, em sua luta pela sobrevivência, exerce uma forte influência sobre o seu comportamento inovativo-competitivo, afetando, diretamente, a dinâmica capitalista em seu conjunto. O comportamento adaptativo, que estabelece as bases do processo de seleção, é resultado dessa dinâmica caracterizada por constantes transformações. Nesse sentido, as instituições empresariais têm desempenhado um papel central na mudança econômica capitalista. É por isso que tal dinâmica tem estado atrelada, historicamente, à coevolução das diferentes formas de inovação, que são fortemente influenciadas pelas grandes corporações.

A construção de uma teoria econômica institucionalista evolucionária tem se dado justamente no sentido de compreender as inovações em seus diferentes âmbitos, partindo do estudo de seu agente principal (empresa) e de suas relações internas e com os demais agentes promotores de inovações, a partir de um determinado contexto macroinstitucional. ${ }^{16}$ Nesse sentido, a compreensão dos avanços tecnológicos passa pelo entendimento da relação que estabelecem com as inovações organizacionais e institucionais. Compreender a importância dessas últimas é fundamental para se tratar do ambiente de seleção e do comportamento da empresa em diferentes paradigmas tecno-econômicos (DOSI, 1988; PEREZ, 2001).

Ainda que o avanço tecnológico continue sendo a força propulsora do processo de mudança (Nelson, 2002), necessita de tecnologias sociais para a sua

15 Não se trata da capacidade individual de aprendizado, dado que o processo de aprendizado é um fenômeno essencialmente coletivo, sobretudo no que se refere à estrutura organizacional da empresa e seu transbordamento para a sociedade, como ressaltado por Lundvall (2007).

16 A teoria da regulação (TR), caracterizada como institucionalista e marxista ao demonstrar como as instituições garantem a reprodução de um sistema contraditório e cheio de tensões como o capitalista, observa claramente que a configuração macroeconômica - expressa na forma de inserção do país no regime internacional, na concorrência, na forma de estado, na gestão monetária e na relação salarial - é fundamental para o progresso técnico e a continuidade da acumulação do capital (FARIA, 2001). Para uma explicação sobre a TR, ver Boyer (1990). 
implementação, difusão, etc. É nesse sentido que a mudança de paradigma (da produção em série para as redes flexíveis, e assim por diante) ${ }^{17}$ representa uma necessidade capitalista de adequação do sistema para melhor desenvolver e processar a capacidade inovativa tecnológica física, própria da dinâmica capitalista.

Desse modo, as redes de empresas, como uma importante inovação organizacional do século XX, têm exercido forte influência sobre o processo de aprendizado, a difusão do conhecimento e as inovações tecnológicas (físicas e sociais). Ao abrangerem os âmbitos interno e externo das empresas simultaneamente, as inovações organizacionais atuam como tecnologias sociais institucionalizadas, constituindo-se em uma importante fonte de motivação para a promoção de inovações tecnológicas e também institucionais, influenciando o desempenho das economias no paradigma em curso. Isso reforça a relação de dependência entre o ambiente micro-organizacional e o macroinstitucional, reforçando a incerteza em relação ao desempenho das economias nacionais que não compõem o núcleo dinâmico do sistema.

A História tem demonstrado que as diferentes formas de inovação adquirem uma crescente importância econômica a partir da sua difusão, que, por sua vez, depende de condições institucionais favoráveis. Sem essa combinação, as possibilidades de inovar e os efeitos da inovação são restritos.

Ainda que não seja uma exclusividade do capitalismo, é nesse sistema que as inovações passam a ser, além de meio, também fim da transformação econômica. Ao mesmo tempo em que são desenvolvidas e adotadas tecnologias adequadas às necessidades econômicas, criam-se possibilidades para um constante aperfeiçoamento das condições produtivas associadas às mudanças nos padrões de produção e consumo: a tecnologia transforma-se em uma necessidade de oferta (pusch) e de demanda (pull). Mesmo que isso não torne o progresso técnico linear e previsível, tem indicado a sua permanente ocorrência, sobretudo quando se considera a amplitude das suas possibilidades, que é crescente a partir das outras formas de inovação, com as quais tem se articulado ao longo do tempo, como demonstrado na última mudança de paradigma tecno-econômico.

As instituições que deram suporte às transformações ao longo da história, culminando com um modo de produção com elevada concentração de capital, também têm contribuído para sustentar essa situação. Daí a ideia amplamente difundida de que, apesar de suas contradições, acentuadas nas crises, o capitalismo teria um caráter autossustentável e, para tanto, continuaria sendo fundamental o permanente fluxo de inovações. Em outros termos, a base material de transformação (avanço tecnológico) seria também um importante ponto de sustentação desse processo e, por isso, as instituições capitalistas (públicas e privadas, formais

Ver Perez (2001). 
e informais) teriam cada vez mais se voltado para garantir o fluxo contínuo de inovações (materiais e imateriais).

A concentração de capital, por parte de uma instituição fundamental do capitalismo (empresa) revelaria, sobretudo ao longo da segunda metade do século $\mathrm{XX}$, a estreita relação existente entre o caráter puramente tecnológico da inovação e suas outras formas de manifestação. Criou-se, a partir dessa relação, um mecanismo de autorreforço do sistema na medida em que as inovações tecnológicas, organizacionais e institucionais têm extrapolado a esfera da unidade produtiva e se difundido socialmente. Em suma, como meio e fim, as inovações passaram a constituir a sua própria base evolutiva, ou seja, além de epicentro, tornaram-se base de sustentação da evolução capitalista.

A partir dessa perspectiva analítica, ampliam-se as bases de compreensão das inovações enquanto fatores sistêmicos, portanto também se acumulando de forma desequilibrada entre as diferentes economias nacionais, ainda que estas possuam estreitas relações entre si. Essa perspectiva possibilita uma análise das diferenças tecnológicas existentes entre as economias nacionais, dadas as singularidades de suas trajetórias, especificamente no que se refere à forma como têm sido estruturados, desenvolvidos e difundidos os processos inovativos. Em síntese, a análise das singularidades de economias nacionais, em perspectiva histórica, a partir dessa abordagem, auxilia na compreensão da manutenção das diferenças que se perpetuam entre as economias, sobretudo no que se refere à inovação, ainda que haja um mundo mais integrado do ponto de vista produtivo e organizacional, como revelado pelo fenômeno das CGVs.

\section{Alguns Elementos acerca do Atraso Inovativo Brasileiro}

Ao longo da história, desde a primeira revolução industrial até meados do século XX, vários autores ressaltaram a importância das inovações para o desempenho das economias (pelo menos de Smith a Schumpeter), mas uma busca mais apurada pela compreensão do processo inovativo, em sua multidimensionalidade, constitui-se um fato contemporâneo, cujas interpretações têm considerado as singularidades nacionais, a partir de relações internas e internacionais. Fica evidente que essa perspectiva não trata da existência de leis que levariam as diferentes economias a um processo de convergência tecnológica, na medida em que o capitalismo industrial se difundisse globalmente, como tem sido enfatizado pelo mainstream economics há décadas.

Conforme Dosi (1988), o advento de uma nova revolução tecnológica com uma mudança de paradigma tecno-econômico, ocorrida na década de 1970, viria reforçar a necessidade de compreensão das inovações como um fenômeno sistêmico, e não como um processo restrito ao avanço tecnológico físico (engenharia 
produtiva). Daí a crescente importância, desde a década de 1980, dedicada ao estudo dos sistemas de inovação (nacionais, mas também setoriais e locais) e as singularidades da sua evolução. As trajetórias econômicas nacionais passaram a ser avaliadas a partir da capacidade de geração endógena (autônoma) de inovações, considerando-se, contudo, como as tecnologias que modificam a estrutura de produção mundial são apropriadas pelas diversas nações. Perez (2004), por exemplo, demonstra que as melhores oportunidades tecnológicas se abrem nos momentos iniciais de uma revolução tecnológica, isto é, quando o conhecimento associado às tecnologias é público e a rentabilidade das inovações ainda é alta.

Nesse sentido, a forma como um país se insere na dinâmica capitalista internacional condiciona suas potencialidades de inovação, sobretudo se considerada a perspectiva de desenvolvimento de um sistema nacional de inovação (SNI) (FREEMAN, 1995) em economias cada vez mais integradas em CGVs,$^{18} \mathrm{em}$ que o agente central da inovação é a grande corporação transnacional. Portanto, a modernização, associada à estrutura produtiva, não é condição suficiente para que uma economia nacional siga com êxito seus objetivos de emparelhamento tecnológico (catching up). Além disso, o acesso fácil e relativamente barato à tecnologia disponível no mercado internacional, em parte difundido sob a forma de IED, tende a contribuir para uma menor exigência de formação de um SNI, como tem sido contrastado em estudos comparativos entre Brasil e Coreia do Sul (CANUTO, 1993, 1994; COUTINHO, 2000; VIOTTI, 2001). Isso significa que as tecnologias tendem a se disseminar para nações menos desenvolvidas quando estão em fase de maturação, encontrando mercados saturados e baixa rentabilidade para firmas inovadoras. Com produtos já amplamente consumidos nos países desenvolvidos, as tecnologias são facilmente operadas e oferecem poucas condições de alavancar o desenvolvimento dos países que não são epicentro das revoluções tecnológicas.

As diferentes trajetórias das economias nacionais têm demonstrado que o atraso é uma condição relativa (AMSDEN, 2009; AREND, 2014), mas que, ao mesmo tempo, pode ser subordinada (CHESNEIS, 1996; SAWAYA, 2006; STRACHMAN, 2016). O emparelhamento tecnológico é um alvo móvel (PEREZ, 2001), condicionado pela evolução conjunta das diferentes formas de inovação. A história recente do capitalismo tem permitido uma compreensão mais adequada desse processo, o que tem servido de laboratório para as análises institucionalista e evolucionária de forma conjunta, implicando uma compreensão mais adequada da transformação econômica.

Utilizar-se dessa perspectiva para analisar a economia brasileira a partir da intenção de industrialização nacional (FONSECA, 2003) amplia as possibilidades de compreensão dos motivos do nosso atraso relativo, principalmente a partir

18 Para uma análise sintética da inserção da economia brasileira nas CGVs, ver Sturgeon et al. (2013) e Araújo Jr. (2013). Para um comparativo com outros países, ver Arend (2014). 
da opção deliberada pela atração de capital estrangeiro, sobretudo a partir da década de 1950. Considerava-se, em grande medida, que o acesso à inovação, através da ETN, era sinônimo de desenvolvimento tecnológico, ou seja, havia um entendimento equivocado acerca da dinâmica produtiva e inovativa das ETNs a partir das suas relações com diferentes economias nacionais: valia a lógica do mainstream. Superestimavam-se os efeitos de transbordamento decorrentes da atração de capital produtivo estrangeiro. Ficaria como parte do aprendizado a ideia de que a difusão tecnológica não se limita ao acesso físico, mas à capacidade de apropriação e reprodução contínua dos processos inovativos.

Furtado (1950) já havia observado que o progresso técnico, na forma como evolui nas economias menos desenvolvidas, acaba agravando seus problemas estruturais (desemprego, subemprego, concentração de renda, heterogeneidades sociais e econômicas, entre outras). Influenciadas pelo perfil da demanda, que tende a ser cópia (mimetismo) dos padrões de consumo das economias desenvolvidas, as inovações se limitam a simples disseminação de técnicas já conhecidas, e não a sua criação. O agente desse progresso técnico, que na maioria das vezes não se adapta à estrutura das economias em desenvolvimento, são as empresas transnacionais, que, para Furtado $(1980,2002)$, ampliam a dependência tecnológica na medida em que controlam as inovações de acordo com seus objetivos.

Nesse caso, conforme Gomes (2006), seria necessário desenvolver mecanismos internos (dentro do país) que viabilizassem a adesão das ETNs à realização de investimentos em atividades inovativas, como PED, o que, entretanto, tem sido restrito em economias como a brasileira, como observam Cassilato et al. (2014), Pereira e Dathein (2015) e Chiarini (2016).

Entende-se que as grandes empresas são as principais responsáveis pelos processos de inovação tecnológica e mudanças organizacionais, desempenhando papel fundamental no desenvolvimento econômico dos países capitalistas. As grandes empresas também têm sido as principais responsáveis pela criação e difusão das inovações organizacionais, que, associadas às tecnológicas, desenvolvem uma combinação-chave para o processo de mudança, inclusive institucional, nas diferentes economias. Trata-se de um processo de coevolução de tecnologias (físicas e sociais), estruturas econômicas (produtivas, organizacionais, comerciais, etc.) e instituições (CIMOLI; KATZ, 2002; NELSON, 2002), que, de forma articulada, condiciona o desempenho das economias. Por isso, as trajetórias econômicas capitalistas têm estado cada vez mais condicionadas ao comportamento das ETNs, como no caso brasileiro. Como ressalta Chesnais (1996), a internacionalização da tecnologia se dá, basicamente, através de cinco dimensões,$^{19} \mathrm{em}$ que

19 Quais sejam: produção privada de tecnologia; aquisição de tecnologia no exterior; intercâmbio cruzado de conhecimentos e tecnologias com o exterior; proteção do conhecimento e das inovações no exterior; e valorização do capital tecnológico fora do país de origem ou em base multinacional. 
a ETN é o único ator participante do sistema com capacidade de atuação em todas elas simultaneamente. Portanto, a forma como se estabelecem as relações (ou alianças) ${ }^{20}$ entre as ETNs e os países hospedeiros, dadas as singularidades das economias nacionais, condicionará os efeitos derivados de tais relações, ou seja, tende a reforçar as assimetrias nacionais.

Por ser subentendida (em função de seu componente tácito), a tecnologia acessada pelas economias em desenvolvimento, principalmente sob a forma de IEDs, normalmente está em descompasso com as formas de organização produtiva do país hospedeiro (AMSDEN, 2009). Como destaca Amsden (2009, p. 105): "Em tese, a transferência tecnológica deveria habilitar um país atrasado a cumprir normas de produtividade mundiais. Na prática, [...] a melhor transferência tecnológica raramente atinge a paridade em produtividade entre comprador e vendedor."

No caso brasileiro, a industrialização acelerada, em grande medida condicionada à atração de IED, revelaria que a expansão produtiva nacional ocorreria sem a necessidade de um avanço tecnológico autônomo, conforme destacado por Furtado (1980) e Dalhman (1984). É nesse sentido que a transferência tecnológica se dá de forma limitada, ficando em grande medida restrita à própria estrutura produtiva e organizacional da empresa estrangeira, com efeitos de transbordamento limitados (PEREIRA; DATHEIN, 2015; CHIARINI, 2016). Como destaca Chiarini (2016), a transferência tecnológica, via IED na economia brasileira, tem se dado, sobretudo, de forma vertical (entre matriz e filiais), ao passo que a transferência horizontal (entre ETNs e empresas nacionais) tem sido bastante restrita, situação que caracterizaria a inércia estrutural da base produtiva industrial brasileira, cujas raízes se encontram no Processo de Substituição de Importações (PSI).

A concepção de que todo atraso é uma condição relativa que pode ser superada permeia o ideário desenvolvimentista brasileiro desde a era Vargas. São vários os estudos, em grande medida, tomando como referência inicial as pesquisas e proposições oriundas do estruturalismo cepalino, ${ }^{21}$ dedicados à compreensão do desenvolvimento econômico brasileiro, em regra perseguindo um modelo capitalista industrial, visando atingir o emparelhamento tecnológico com as economias desenvolvidas.

Se, de fato, as ações deliberadas para o desenvolvimento econômico nacional começaram efetivamente na década de 1930, seria somente com a crise, o esgotamento e o definitivo abandono do PSI como modelo de desenvolvimento, na década de 1980, que ficaria evidente as dificuldades de superação do atraso relativo da economia brasileira. Por mais que a industrialização, durante o PSI, fosse compreendida como sinônimo de desenvolvimento econômico, ${ }^{22}$ a baixa incor-

$20 \quad$ Ver Evans (1980).

21 Para mais detalhes sobre o pensamento cepalino, ver Bielchowsky (2000).

22 No início dos anos 1970, autores como Celso Furtado, Conceição Tavares e José Serra contestam 
poração dos processos inovativos (tecnologias físicas e sociais), que continuavam sendo, em sua maioria, geradas no exterior, revelava a condição dependente e subordinada à lógica de expansão do capital transnacional, refletida no atraso relativo da economia brasileira, dada a sua industrialização baseada em grande medida na atração de IED. Nesse sentido, foi possível industrializar-se sem desenvolver-se, como destacam Furtado (1980) e Tavares (1998).

Ainda que a intenção de transformar o Brasil em uma economia capitalista industrializada esteja associada ao governo Vargas (FONSECA, 2003), a busca pelo emparelhamento tecnológico com as economias desenvolvidas ficaria evidenciada em dois momentos: no início e no final da segunda metade do século XX (CASTRO, 2003), em que os governos ampliam e aprofundam a relação da economia nacional, sobretudo no que se refere ao setor industrial de transformação, com o capital estrangeiro, financeiro e produtivo. Trata-se de dois momentos históricos muito importantes do ponto de vista de estratégias de desenvolvimento: o primeiro (anos 1950) sob forte influência da concepção de necessidade de associação com o capital estrangeiro, com o Estado exercendo um papel produtivo relevante, aproveitando-se das condições internacionais favoráveis (CURADO; CRUZ, 2008); e o segundo (anos 1990) em que as críticas ao modelo industrializante (PSI) reduzem a importância da indústria como núcleo dinâmico da economia nacional, inclusive no que se refere à capacidade de geração de inovações, mas reforçam a necessidade de acesso à tecnologia importada, em que o Estado adota uma postura de regulador da atividade econômica, transferindo para as ETNs o protagonismo das expectativas de desenvolvimento (FRANCO, 1998).

As duas tentativas de emparelhamento tecnológico na economia brasileira (CASTRO, 2003) ocorreram em dois diferentes paradigmas tecno-econômicos. A primeira tentativa, associada ao período de internacionalização produtiva do PSI (a partir do governo JK), foi bem-sucedida do ponto de vista da mudança estrutural da economia brasileira a partir do setor industrial, mas não criou condições internas suficientemente favoráveis à geração endógena de inovações compatíveis com a transição de paradigmas (FURTADO, 1980; KATZ, 2000; SUZIGAN; FURTADO, 2010). Por sua vez, a segunda tentativa de emparelhamento tecnológico, caracterizada pela abertura econômica e pela reestruturação e modernização produtiva da indústria brasileira a partir da década de 1990, revelaria tanto a dependência quanto a subordinação tecnológica aprofundada na medida em que as ETNs continuaram sendo consideradas os agentes fundamentais da inovação, e também do desenvolvimento, na economia nacional (FRANCO, 1998).

A exemplo do ocorrido durante o PSI, a modernização produtiva do setor industrial retorna ao Brasil na segunda metade da década de 1990, mas não traz

a linearidade dessa associação. Para uma síntese dos principais argumentos, ver Curado (2013, p. 619-627). 
a internalização dos processos inovativos. Por isso, a estrutura produtiva industrial (centro das inovações em economias em desenvolvimento) segue sendo atrelada ao velho paradigma tecno-econômico (metal-mecânico-químico) (AREND; FONSECA, 2102), incorporando os avanços do paradigma das redes flexíveis (microeletrônica) a partir do exterior, de forma exógena, seguindo a lógica da convergência expressa no pensamento dominante.

Como ressalta Arend (2014, p. 376), o atraso relativo da economia brasileira, em comparação com os países em que predominam atividades industriais dos segmentos emergentes (microeletrônica, telecomunicações, biotecnologia e novos materiais), condiciona o processo de modernização nacional ao mesmo tempo que amplia e aprofunda sua relação com as ETNs. Essa conjunção de fatores, a despeito de possibilitar um maior acesso às inovações, acabaria por colocar a indústria brasileira em uma condição subordinada ante a nova divisão internacional do trabalho, em que as atividades industriais nacionais que se destacam são intensivas em mão de obra e recursos naturais, ao passo que as atividades intensivas em tecnologia do paradigma microeletrônico vêm perdendo participação no valor da transformação industrial (VTI) desde a década de 1990.

Como destacam Coriat e Dosi (2007), as inovações necessitam de ambiente adequado para a sua geração e difusão, implicando a endogeneização de processos inovativos, o que difere significativamente de ter acesso fácil e relativamente barato aos seus resultados.

As limitações na coevolução das tecnologias físicas e sociais ao longo do processo de industrialização da economia brasileira seguem presentes em um contexto de desindustrialização e inserção da indústria nacional nas CGVs, situação corroborada pelo aumento do fluxo de IEDs como estratégia de retomada do crescimento nos anos 1990, que contrasta com as dificuldades de natureza institucional, organizacional e produtiva internas.

Apesar de ser um importante destino de IEDs (quarto maior receptor mundial em 2012), o Brasil tem se caracterizado pelo baixo investimento em PEBD por parte das ETNs (CHIARINI, 2016), que optam por modernizar sua estrutura produtiva local (filiais), como destacado anteriormente, em grande medida através da aquisição de máquinas e equipamentos importados. Essa situação se explicita no crescimento da participação das ETNs no comércio internacional brasileiro, ${ }^{23}$ ao mesmo tempo que há um crescente déficit tecnológico nacional. ${ }^{24}$

23 A participação das ETNs no total das exportações brasileiras passou de 46,8\%, em 1995, para $54,9 \%$, em 2005, ao passo que a participação no total das importações, nesse mesmo período, foi de 38,8\% para 61,8\% (BANCO CENTRAL DO BRASIL, 2015).

24 O déficit tecnológico (saldo negativo no comércio exterior de produtos de alta e média alta intensidade tecnológica), que tem crescido ao longo dos últimos anos (11,5\% de 2012 para 2013, chegando a um montante de US $\$ 93$ bilhões), é um indicador da dependência tecnológica nacional. Quanto maior o déficit, tanto maior tende a ser a dependência tecnológica (SOCIEDADE BRASILEIRA PRÓ-INOVAÇÃO TECNOLÓGICA, 2014). 
Conforme observam Pereira e Dathein (2015), baseando-se em dados da Pesquisa de Inovação Tecnológica (Pintec/IBGE) para o período 2000-2008, destaca-se o esforço inovativo (dispêndio em atividades inovativas como percentual da receita líquida de vendas) das grandes empresas (500 ou mais pessoas ocupadas) nacionais e estrangeiras da indústria de transformação brasileira na aquisição de máquinas e equipamentos como forma de atualização tecnológica da estrutura produtiva dessas empresas, inclusive em detrimento do esforço inovativo em PEBD.

Fica evidente que a inovação no Brasil carece de um caráter multidimensional. A fragilidade da base institucional voltada para políticas de inovação (KATZ, 2000; CIMOLI et al., 2007; SUZIGAN; FURTADO, 2010) se reflete no fato de a parte física evoluir, sobretudo, via importação de tecnologia, em descompasso com as demais esferas da dinâmica inovativa. Nesse sentido, o Brasil cumpre um importante papel do ponto de vista sistêmico, ou seja, para o conjunto das economias capitalistas avançadas, que concentram grande parte das inovações e necessitam de ampliação de mercados para absorção da capacidade produtiva gerada pelas novas tecnologias. Entende-se que essa situação abarca um dos aspectos que caracteriza a contradição da subordinação da economia brasileira, dado que as inovações seriam introduzidas, predominantemente, via importação de tecnologias, mesmo em atividades industriais em que predominam ETNs.

As trajetórias acabam por definir a importância relativa dos agentes da inovação, criando um condicionante histórico (lock in) (ARTHUR, 1989) para o desenvolvimento de processos inovativos por parte das economias nacionais. Nesse sentido, a opção pela associação com o capital estrangeiro, facilitando o acesso às diferentes formas de inovação por parte da economia brasileira, em descompasso com o desenvolvimento tecnológico endógeno (autônomo) durante o PSI, acabaria dificultando o ingresso no paradigma das redes flexíveis de forma ativa (VIOTTI, 2001), ao mesmo tempo que aprofundaria a dependência tecnológica das ETNs.

Em síntese, vários estudos recentes, alguns mencionados ao longo desta seção, têm corroborado perspectivas históricas em relação às dificuldades de desenvolvimento econômico nacional por parte da economia brasileira, dado que grande parte das possibilidades de avanço tecnológico têm estado, em grande medida, subordinada ao comportamento das ETNs: empresas que operam em uma lógica sistêmica de inovação, levando em consideração as singularidades nacionais, daí resultando também a relação de dependência e subordinação tecnológica de economias como a brasileira.

Nesse sentido, a evolução do SNI no Brasil tem sido descontínua e concentrada em algumas poucas atividades (PEREIRA; DATHEIN, 2015). Mesmo na perspectiva de um sistema nacional de inovação aberto (UNITED NATIONS CONFERENCE ON TRADE AND DEVELOPMENT, 2005), com crescente participação do 
capital estrangeiro, os resultados da inserção do Brasil nas CGVs têm demonstrado que a participação do país tem se concentrado em atividades de menor intensidade tecnológica e que exigem poucos investimentos em inovação dentro das fronteiras nacionais, inclusive por parte das ETNs (CASSIOLATO et al., 2014).

\section{Considerações Finais}

À medida que as diferentes formas de inovação coevoluem, se autorreforçam. Essa interação funciona como epicentro e, ao mesmo tempo, como base de sustentação da evolução capitalista, dado que as inovações tecnológicas e organizacionais normalmente avançam mais rapidamente do que as inovações institucionais, cuja inércia, por vezes, é fundamental para a evolução daquelas, bem como para o status quo da lógica capitalista de acumulação de capital, que está em grande medida centrada na inovação. A inércia institucional não impede o avanço tecnológico, mas pode impor limites às possibilidades de mudança permanente, exigidas pela evolução sistêmica, contribuindo para que algumas economias permaneçam em sua condição de atraso relativo, e também subordinado, ainda que sejam fundamentais para o funcionamento do sistema. Manter a ordem implica promover e difundir inovações constantemente, mas de forma concentrada. Ao contrário do que argumenta o mainstream economics, a convergência não é um objetivo concreto para a maior parte das economias industrializadas, mesmo que tenhas aderido a mecanismos de crescente liberalização financeira, produtiva e comercial.

No caso brasileiro, a persistência do atraso relativo, no que se refere às inovações, é em grande medida um reflexo da forma subordinada como a economia nacional tem se inserido no sistema capitalista, através de suas relações (alianças) com o capital estrangeiro, sobretudo na forma de ETNs. É nesse sentido que as tentativas de emparelhamento tecnológico têm dado resultados positivos do ponto de vista produtivo (modernização), ao mesmo tempo que têm efeitos limitados no que se refere aos aspectos inovativos e sua sustentação no longo prazo. As duas tentativas de emparelhamento tecnológico, adotadas como estratégias de desenvolvimento econômico nacional, acabariam se consolidando como aprofundamento da dependência e da subordinação tecnológica, situação típica de economias retardatárias que não criam condições de ruptura com o atraso relativo, na medida em que perpetuam políticas industriais inadequadas para o desenvolvimento de inovações tecnológicos endogenamente (dentro das fronteiras nacionais).

Como destacado anteriormente, as inovações necessitam de ambiente institucional favorável à sua propagação (tecnologias sociais e SNI), bem como de estruturas institucionais e de regulação que garantam demanda para as inovações 
em desenvolvimento. No caso brasileiro, não houve continuidade na conjugação desses fatores ao longo da segunda metade do século XX, o que é corroborado pela forma como foi atraído o capital produtivo estrangeiro, com destaque para o protagonismo que se concedeu às ETNs, sobretudo na década de 1990.

A facilidade de absorção de inovações geradas exogenamente tem sido um fator condicionante das dificuldades de desenvolvimento inovativo endógeno na economia brasileira. Por um lado, o maior acesso à tecnologia física não tem sido garantia de emparelhamento tecnológico, por outro, tem sido fundamental para a dinâmica capitalista ao contribuir para a expansão da capacidade produtiva e inovadora em escala global. Portanto, em vez de um desenvolvimento dependente associado (CARDOSO; FALETTO, 2004; CARDOSO, 1995), observou-se, na economia brasileira ao longo da segunda metade do século XX, uma relação dependente, mas subordinada à lógica da expansão do capital transnacional.

\section{Referências}

AMSDEN, A. A ascensão do "resto": os desafios do ocidente de economias com industrialização tardia. São Paulo: Editora da UNESP, 2009.

ARAÚJO JÚNIOR, J. T. Fragmentação da produção e competitividade internacional: o caso brasileiro. Revista Brasileira de Comércio Exterior, Rio de Janeiro, n. 115, p. 42-51, 2013.

AREND, M. A industrialização no Brasil ante a nova divisão internacional do trabalho. In: CALIXTRE, A. B.; BIANCARELLI, A.; CINTRA, M. A. M. (Orgs.). Presente e futuro do desenvolvimento no Brasil. Brasília: IPEA, 2014. p. 5-42.

AREND, M.; FONSECA, P. C. D. Brasil (1955-2005): 25 anos de catching up, 25 anos de falling behind. Revista de Economia Política, São Paulo, v. 32, n. 1, p. 33-54, 2012.

ARTHUR, W. B. Competing technologies, increasing returns, and lock-in by historical events. The Economic Journal, v. 99, n. 394, p. 116-131, 1989.

AYDIN, D. G.; TAKAY, B. A.; OZIL, H. Two levels of abstraction in Schumpeter and Marx: history and capitalism. International Research Journal of Finance and Economics, v. 50, n. 50, p. 17-25, 2010.

BANCO CENTRAL DO BRASIL. Censo de capitais estrangeiros no país. Brasília, 2015. Disponível em: < http://www.bcb.gov.br/?CENSOCE > . Acesso em: abril de 2015.

BIELCHOWSKY, R. (Org.). Cinqüenta anos de pensamento na CEPAL. Rio de Janeiro: Record, 2000 .

BOYER, R. A teoria da regulação: uma análise crítica. São Paulo: Nobel, 1990.

CAMPOLINA, B.; DINIZ, C. C. Crise global, mudanças geopolíticas e inserção do Brasil. Revista de Economia Política, São Paulo, v. 34, n. 4, p. 638-655, out./dez. 2014. 
CANO, W. A desindustrialização no Brasil. Economia e Sociedade, Campinas, v. 21, n. especial, p. 831-851, 2012.

CANUTO, O. Brasil e Coréia do Sul: os (des)caminhos da industrialização tardia. São Paulo: Nobel, 1994.

CARDOSO, F. H. Desenvolvimento: o mais político dos temas econômicos. Revista de Economia Política, São Paulo, v. 15, n. 4, p. 148-155, 1995.

CARDOSO, F. H.; FALETTO, E. Dependência e desenvolvimento na América Latina: ensaio de interpretação sociológica. Rio de Janeiro: Civilização Brasileira, 2004.

CASSIOLATO, J. E. et al. Transnational corporations and the Brazilian national system of innovation. In: CASSIOLATO, J. E. et al. (Eds.). BRICS National Systems of Innovation: transnational corporations and local innovation. [S. 1.]: Edward Elgar, 2014. Disponível em: <https:/www.researchgate.net/publication/274699868>. Acesso em: 20 nov. 2014.

CASSIOLATO, J. E.; LASTRES, H. M. M. Sistemas de inovação e desenvolvimento: as implicações de política. São Paulo em Perspectiva, São Paulo, v. 19, n. 1, p. 34-45, 2005.

CHESNAIS, F. A mundialização do capital. São Paulo: Xamã, 1996.

CHIARINI, T. A inércia estrutural da base produtiva brasileira: o IDE e a transferência internacional de tecnologia. Revista de Economia Política, São Paulo, v. 36, n. 2, p. 286-308, 2016.

CIMOLI, M. et al. Instituições e políticas moldando o desenvolvimento industrial: uma nota introdutória. Revista Brasileira de Inovação, Campinas, v. 6, n. 1, p. 55-85, 2007.

CIMOLI, M; KATZ, J. Structural reforms, technological gaps and economic development: a Latin American perspective. Santiago, Chile: CEPAL, 2002. (Serie Desarrollo Productivo, n. 129, Aug. 2002).

COMMONS, J. R. Institutional economics. The American Economic Review, v. 21, p. 648-657, 1931.

CORIAT, B.; DOSI, G. The institutional embeddedness of economic change: an appraisal of the 'evolutionary' and 'regulationist' research programmes. IIASA Working Paper. IIASA, Laxenburg, Austria: WP-95-117. Disponível em: < http://esnie.org/pdf/textes_2007/Dosichap-12.pdf> . Acesso em: 15 ago. 2007.

COUTINHO, L. Coréia do Sul e Brasil: paralelos, sucesso e desastres. In: FIORI, J. L. (Org.). Estados e moedas no desenvolvimento das nações. Rio de Janeiro: Vozes, 2000. p. 351-377.

CURADO, M.; CRUZ, M. J. V. Investimento direto externo e industrialização no Brasil. Revista de Economia Contemporânea, Rio de Janeiro, v. 12, n. 3, p. 399-431, 2008.

CURADO, M. Industrialização e desenvolvimento: uma análise do pensamento econômico brasileiro. Economia e Sociedade, Campinas, v. 22, n. 3, p. 609-640, 2013. 
DAHLMAN, C. J. Foreign technology and indigenous technological capability in Brazil. In: FRANSMAN, M.; KING, K. (Ed.). Technological capability in the third world. London: Macmillan Press, 1984. p. 317-334.

DOSI, G. Sources, procedures and microeconomic effects of innovation. Journal of Economic Literature, v. 26, n. 3, p. 1120-1171, Sept. 1988.

ELLIOT, J. E. Marx and Schumpeter on capitalism's creative destruction: a comparative restatement. The Quarterly Journal of Economics, v. 95, n. 1, p. 45-68, 1980.

EVANS, P. B. A tríplice aliança: as multinacionais, as estatais e o capital nacional no desenvolvimento dependente brasileiro. Rio de Janeiro: Zahar, 1980.

FARIA. L. A. E. As formas institucionais de estrutura: do micro ao macro na teoria da regulação. Ensaios FEE, Porto Alegre, v. 22, n. 1, p. 187-204, 2001.

FERRAZ, L. P. C.; GUTIERRE, L.; CABRAL, R. A indústria brasileira na era das cadeias globais de valor. In: BARBOSA, N. et al. (Orgs.). Indústria e desenvolvimento produtivo no Brasil. Rio de Janeiro: Elsevier; FGV, 2015.

FONSECA, P. C. D. Sobre a intencionalidade da política industrializante do Brasil na década de 1930. Revista de Economia Política, São Paulo, v. 23, n. 1, p. 33-148, 2003.

FREEMAN, C. Inovação e ciclos longos de desenvolvimento econômico. Ensaios FEE, Porto Alegre, v. 5, n.1, p. 5-20, 1984.

. The 'National system of innovation' in historical perspective. Cambridge Journal of Economics, v. 19, p. 5-24, 1995.

FURTADO, C. Estado e empresas transnacionais na industrialização periférica. Revista de Economia Política, v. 1, n. 1, p. 41-49, 1980.

. Formação de capital e desenvolvimento econômico. Rio de Janeiro, 1951. Disponível em: < http://www.centrocelsofurtado.org.br/arquivos/image/201109010910270.MD1_0_195. pdf $>$. Acesso em: 18 set. 2014.

. Metamorfoses do capitalismo. [S. 1], 2002. Disponível em: <http://www. redcelsofurtado.edu.mx/archivosPDF/furtado1.pdf>. Acesso em: 10 jun. 2002.

GOMES, R. Empresas transnacionais e internacionalização da P\&D: elementos de organização industrial da economia da inovação. São Paulo: Editora da UNESP, 2006.

HODGSON. G. M. Choice, habit and evolution. Journal of Evolutionary Economics, v. 20, n. 1, p. 1-18, 2010.

. Downward causation: some second thoughts. Watford, UK, 2011. Disponível em: <http://www.geoffrey-hodgson.info/downward-causation.htm>. Acesso em: 27 maio 2011. 1997.

. Economia e evolução: o regresso da vida à teoria econômica. Lisboa: Celta Editora, 
. The hidden persuaders: institutions and individuals in economic theory. Cambridge Journal of Economics, Oxford, v. 27, n. 2, p. 159-175, 2002.

. What are institutions? Journal of Economic Issues, v. XL, n. 1, p. 1-25, 2006.

. Institutions and individuals: interaction and evolution. Organization Studies, v. 28, n. 1, p. 95-116, 2007.

Institutional economics: surveyng the 'old' and the 'new'. Metroeconomica, v. 44, n. 1, p. 1-28, 1993.

KATZ, J. A dinâmica do aprendizado tecnológico no período de substituição de importações e as recentes mudanças estruturais no setor industrial da Argentina, do Brasil e do México. In: KIM, L.; NELSON, R. R. (Org.). Tecnologia, aprendizado e inovação: as experiências das economias de industrialização recente. Campinas: Editora da Unicamp, 2000.

LUNDVALL, B.-Â. National innovation systems: analytical focusing device and policy learning tool. Copenhagen, Denmark: Swedish Institute for Growth Policy Studies, 2007. (Working Paper n. 4, 2007).

The social dimension of the learning economy. Copenhagen, Denmark: Danish

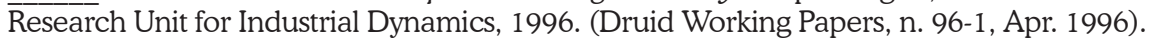

MARX, K. O capital. São Paulo: Difel, 1983. Tomos 1 e 2.

NASSIF, A. Há evidências de desindustrialização no Brasil? Revista de Economia Política, São Paulo, v. 28, n. 1, p. 72-96, 2008.

NELSON, R. R. Bringing institutions into evolutionary growth theory. Journal of Evolutionary Economics, v. 12, n. 1, p. 17-28, 2002.

. Economic development from the perspective of evolutionary economic theory. Tallinn, Estonia: Tallinn University of Technology, 2006. (Working Papers in Technology, Governance and Economic Dynamics, n. 2, Jan. 2006). Disponível em: < http://technologygovernance. eu/files/main/2006013112494141.pdf > . Acesso em: 11 maio 2011.

The co-evolution of technology, industrial structure and supporting institutions. In: DOSI, G.; TEECE, D. J.; CHITRY, J. (Ed.). Technology, organization and competitiveness: perspective on industrial and corporate change. London, UK: Oxford University Press, 1998. p. 319-335.

NELSON, R. R.; WINTER, S. G. Uma teoria evolucionária da mudança econômica. Campinas: Editora da Unicamp, 2005.

NORTH, D. C. Instituciones, cambio institucional e desempeño económico. México: Fondo de Cultura Económico, 1993.

OREIRO, J. L.; FEIJÓ, C. A. Desindustrialização: conceituação, causas, efeitos e o caso brasileiro. Revista de Economia Política, São Paulo, v. 30, n. 2, p. 219-232, 2010.

PENROSE, E. A teoria do crescimento da firma. Campinas: Editora da Unicamp, 2006. 
PEREIRA, A. J.; DATHEIN, R. Impactos do comportamento inovativo das grandes empresas nacionais e estrangeiras da indústria de transformação brasileira no desenvolvimento do sistema nacional de inovação. Estudos Econômicos, São Paulo, v. 45, n. 1, p. 65-96, 2015.

PEREIRA, A. J.; DATHEIN, R.; CONCEIÇÃO, O. A. C. A empresa e seu ambiente de interação: os limites da Teoria dos Custos de Transação e o alcance da Teoria Institucionalista Evolucionária. Economia e Sociedade, Campinas, v. 23, n. 1, p. 33-61, 2014.

PEREZ, C. Cambio estructural y asimilación de nuevas tecnologías en el sistema económico y social. Futures, v. 15, n. 4, p. 357-375, oct. 1983.

. Cambio tecnológico y oportunidades de desarrollo como Blanco móvil. Revista de la $\overline{C E P A L}$, Santiago de Chile, n. 75, p. 115-136, dic. 2001.

. Revoluciones tecnológicas y capital financiero: la dinámica de las grandes burbujas financieras y las épocas de bonanza. México: Siglo XXI, 2004.

ROSENBERG, N. Por dentro da caixa preta: tecnologia e economia. Campinas: Editora da Unicamp, 2006.

SALOMON, J.-J. Morte e ressurreição do capitalismo: a propósito de Schumpeter. Estudos Avançados, São Paulo, v. 5, n. 13, p. 101-122, 1991.

SAWAYA, R. Subordinação consentida: capital multinacional no processo de acumulação da América Latina e Brasil. São Paulo: Annablume; Fapesp, 2006.

SCHUMPETER, J. A. A instabilidade do capitalismo. In: CARNEIRO, R. (Org.). Os clássicos da economia. São Paulo: Atlas, 1997a. p. 68-96.

. Bussiness cycles. New York: McGraw-Hill Book Company, 1939.

. Capitalismo, socialismo e democracia. Rio de Janeiro: Fundo de Cultura, 1961.

. Teoria do desenvolvimento econômico: uma investigação sobre lucros, capital, crédito, juro e o ciclo econômico. São Paulo: Nova Cultural, 1997b.

. The creative response in economic history. The Journal of Economic History, v. 7, n. 2, p. 149-159, 1947.

SOCIEDADE BRASILEIRA PRÓ-INOVAÇÃO TECNOLÓGICA. Monitor do déficit tecnológico: resumo de 2013. Rio de Janeiro, 2014. Disponível em: < http://protec.org.br/noticias/ pagina/30800/Monitor-do-Deficit-Tecnologico-Resumo-de-2013 > . Acesso em: 17 maio 2015.

STRACHMAN, E. Crescimento econômico brasileiro e seus obstáculos - 1930-2015: uma análise histórico-estrutural. München: Universität München, 2016. (Munich Personal RePEc Archive, Paper n. 72697, 22 July 2016). Disponível em: <https://mpra.ub.uni-muenchen. de/72697/>. Acesso em: 29 jul. 2016.

STURGEON, T. et al. O Brasil nas cadeias globais de valor: implicações para a política industrial e de comércio. Revista Brasileira de Comércio Exterior, Rio de Janeiro, n. 115, p. 26-41, abr./jun. 2013. 
SUZIGAN, W.; FURTADO, J. Instituições e políticas industriais e tecnológicas: reflexões a partir da experiência brasileira. Estudos Econômicos, São Paulo, v. 40, n. 1, p. 7-41, 2010.

SUZIGAN, W.; FURTADO, J. Política industrial e desenvolvimento. Revista de Economia Política, São Paulo, v. 26, n. 2, p. 163-185, 2006.

TAVARES, M. C. Crise e ciclo: o movimento recente da industrialização brasileira. Campinas: Universidade Estadual de Campinas; Instituto de Economia, 1998.

UNITED NATIONS CONFERENCE ON TRADE AND DEVELOPMENT. Transnational corporations and the internationalization of RED. World Investment Report (WIR). Geneva, 2005.

VEBLEN, T. B. A teoria da classe ociosa: um estudo econômico das instituições. São Paulo: Livraria Pioneira Editora, 1965.

VIOTTI, E. B. National learning systems: a new approach on technical change in late industrializing economies and evidences from the cases of Brazil and South Korea. Cambridge, MA, USA: Center for International Development, Harvard University, 2001. (Science, Technology and Innovation Discussion Paper, n. 12, 2001).

Recebido em: 16/02/2017. Aceito em: 06/10/2017. 